\title{
Psychophysical Aspects of Public Health in the Oil and Gas Region
}

\author{
Muslima Bashbaeva ${ }^{1}$, Ainur Zinalieva ${ }^{2}$, Gulmira Umarova ${ }^{3}$, Akmaral Baspakova $^{4}$, Ainash Duisenova ${ }^{5 *}$ \\ ${ }^{1}$ Center for Continuous Professional Development, West Kazakhstan Marat Ospanov State Medical University, Aktobe, \\ Kazakhstan, Asia; ${ }^{2}$ Department of Hygienic Disciplines, West Kazakhstan Marat Ospanov State Medical University, Aktobe, \\ Kazakhstan, Asia; ${ }^{3}$ Department of Public Health, West Kazakhstan Marat Ospanov State Medical University, Aktobe, \\ Kazakhstan, Asia; ${ }^{4}$ Department of Management of Scientific and Innovative Activities, West Kazakhstan Marat Ospanov State \\ Medical University, Aktobe, Kazakhstan, Asia; ${ }^{5}$ Disciplines of Social Sciences and Humanities Department, West Kazakhstan \\ Marat Ospanov State Medical University, Aktobe, Kazakhstan, Asia
}

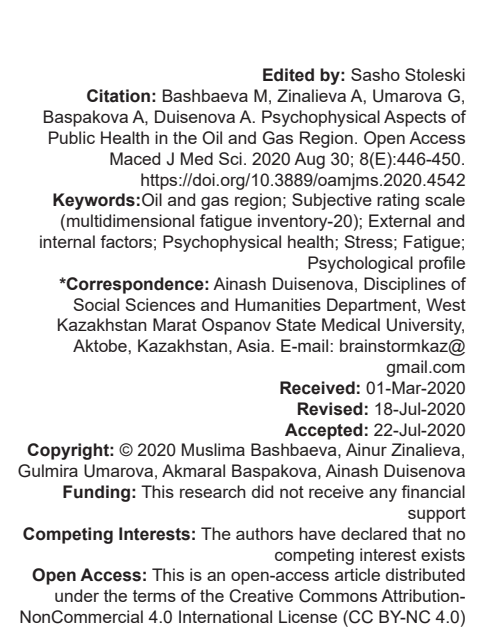

\section{Abstract}

This study attempts to determine whether the prolonged stay of people in an unfavorable environment, in our case the oil and gas $(O G)$ region, affects their psychophysical health, makes them vulnerable, prone to psychosomatic diseases, creates psychological problems, or leads to internal conflicts. Participants (typically healthy people) were asked to answer questions based on the multidimensional fatigue inventory (MFI-20). The scale reflects the following five main dimensions of fatigue: General fatigue, physical fatigue, reduced activity, mental fatigue, and reduced motivation. Three of them, namely general fatigue, physical fatigue, and mental fatigue, are of particular importance for this work. The study revealed the psychological profiles of the population of the study region and concluded that the OG region poses a significant risk to public health with all the ensuing consequences.

\section{Introduction}

The ever-increasing need for energy resources leads not only to the expansion of oil and gas (OG) production but also to an increase in the extent of damage to the environment [1], [2], [3], [4], [5]. Oil production has a devastating effect on the population living in the OG region. The Human Rights Watch organization notes that oil-oriented development has caused severe environmental damage, destroying the livelihoods of many people living in oil-producing communities [6]. The influence of a number of unfavorable production factors on the state of public health against the background of developing fatigue contributes to a reduction in work safety, exposure to various diseases, and affects the quality of life.

US scientists believe that a special threat to the population living in OG producing regions is posed by infectious diseases to which locals have not developed immunities. For example, when workers arrived in the Urarina region in the Peruvian Amazon in the 1990s, they were faced with the outbreak of various diseases, including pertussis and strains of malaria, which had never been observed in this community [6].

Russian and American studies, aimed at finding out how OG development affects the psychophysical health and, in general, the quality of life of oil workers, as well as the population of these regions, made it possible to conclude that oil workers have high levels of psychoemotional stress and anxiety, while residents have "socio-psychological" disorders. The most noticeable negative consequence in this case is stress, as a result of the prolonged effect of external adverse stimuli to the body, leading to nervous strain. It is noted that the development of oil fields carries a tendency for the prevalence of diseases of the peripheral nervous system, arterial hypertension, respiratory diseases, the risk of developing borderline mental disorders, etc. Long-term stress can potentially lead to a weakening of the immune system and create serious psychophysical problems in the form of fatigue (Verkuil et al.). It should be noted that in the case of fatigue, there is a change in the activity of the 
reticular formation, maintaining the level of attention, perception, wakefulness and sleep, general muscle activity, and autonomic regulation. Therefore, extreme environmental requirements can exceed the resources of the human body and create threats to personal wellbeing. da Silva et al. believe that disasters caused by nature and by humans themselves are dangerous and can lead to psychological crises and suicide attempts. They identified three crisis contexts: Disasters, risk, and trauma [1], [7], [8], [9], [10], [11], [12], [13]. In the present study, the risk was taken as the basis. I.P. Pavlov argued that with prolonged exposure to pathological internal and external factors, the central nervous system inevitably depletes itself and its performance decreases sharply [14]. This condition is manifested by a decrease in performance and motivation, fatigue, emotional instability, and sleep disturbances.

At present, human mental health as a field of knowledge is left without due attention. It should be noted that one in four people during their lives might encounter mental health problems, which is fraught with grave consequences in the form of changes in the model of thinking and behavior [14], [15], [16], [17], [18], [19]. In this study, we made an attempt to determine the effects of the environment on the psychophysical state of public health in OG regions and to identify psychological profiles.

The purpose of this study is to determine whether the prolonged stay of people in an unfavorable living environment is reflected in their psychophysical health.

To achieve this purpose, the following tasks were identified:

1. To determine the susceptibility of study participants to various types of fatigue

2. To identify and describe the psychological profiles of the population of the study region.

\section{Materials and Methods}

To determine the psychophysical state of health and identify the psychological profile of the population of the $\mathrm{OG}$ region, the multidimensional fatigue inventory (MFI-20) scale was used. It was developed by Dutch scientists Smets et al. This technique is intended to obtain a subjective quantitative assessment of the overall severity of fatigue and its various aspects. The scale contains 20 statements designed to measure five fatigue dimensions: General fatigue, physical fatigue, reduced activity, reduced motivation, and mental fatigue. Each dimension contains four elements that are rated on a 5-point scale. Scores are summarized, with the highest scores indicating more acute levels of fatigue. Table 1 shows a fragment of the MFI-20 scale.
Table 1: Fragment of the multidimensional fatigue inventory-20 scale

\begin{tabular}{lllllllll}
\hline No & Statement & Answer & & & & & \\
\hline 1 & I feel fit & Yes, that is true & 1 & 2 & 3 & 4 & 5 & No, that is not true \\
2 & $\begin{array}{l}\text { Physically I feel only able } \\
\text { to do a little }\end{array}$ & Yes, that is true & 1 & 2 & 3 & 4 & 5 & No, that is not true \\
3 & I feel very active & Yes, that is true & 1 & 2 & 3 & 4 & 5 & No, that is not true \\
\hline
\end{tabular}

This scale makes it possible to determine the significance level "p," which shows the accuracy of the research results. Significance levels were recorded as decimal fractions (as 0.01). A low value for significance corresponds to a low probability that the experimental results are random. The questioning was carried out by specially trained medical specialists. The results allowed combining the data into homological semantic groups - profiles that reflect various characteristics of the severity or non-severity of fatigue dimensions. Table 2 shows the interpretation of fatigue dimensions.

Table 2: Key to the subjective fatigue rating scale

\begin{tabular}{lll}
\hline No & Fatigue dimensions & Scale answer numbers \\
\hline 1 & General fatigue & $1,5,12,16$ \\
2 & Reduced activity & $3,6,10,17$ \\
3 & Reduced motivation & $4,9,15,18$ \\
4 & Physical fatigue & $2,8,14,20$ \\
5 & Mental fatigue & $7,11,13,19$ \\
\hline
\end{tabular}

Typically, the total number of scores should not exceed 20-30. Statistical processing was performed using the Statistical Package for the Social Sciences version 25 for Windows. According to the sample, the study involved the population of the West Kazakhstan region: Adults aged 18-50 years living near the Karachaganak field in Aksai - 246 people; Berezovka - 188 people; and Uralsk city - 248 people (the control group).

In accordance with the research report, a selfquestioning of the psychophysical state of public health was carried out with a visit to the place of residence of the subjects. The obtained data coincide with the literature on the impact of $O G$ development on the psychophysical state of the population [1], [5], [6], [7], [8], [9], [10], [11].

\section{Results}

The statistical analysis of the data revealed the psychophysical state of the population of the study regions. The results are presented in Table 3.

When comparing the results for men in OG and control regions (CR) in terms of "general fatigue," "mental fatigue," and "reduced motivation," as well as for women in terms of "general fatigue" and "reduced motivation," statistically significant differences $p>0.05$ were found. Table 3 shows that the psychophysical state of health of men and women in the study regions is statistically significantly different for all fatigue dimensions $(p>0.05)$. 
Table 3: Quantitative self-report analysis of the population of the study regions by gender

\begin{tabular}{|c|c|c|c|c|c|c|c|}
\hline Dimension & Gender & Group & $\mathrm{n}$ & Mean & Median & SD & p level \\
\hline \multirow[t]{4}{*}{ General fatigue } & Male & OG & 106 & 9.7 & 9.0 & 3.0 & $p>0.05$ \\
\hline & & $\mathrm{CR}$ & 90 & 8.4 & 10.0 & 3.4 & \\
\hline & Female & OG & 328 & 9.3 & 8.0 & 3.3 & $p>0.05$ \\
\hline & & $\mathrm{CR}$ & 158 & 8.9 & 8.0 & 3.9 & \\
\hline \multirow[t]{4}{*}{ Physical fatigue } & Male & OG & 106 & 9.7 & 8.5 & 3.1 & $p>0.05$ \\
\hline & & $\mathrm{CR}$ & 90 & 8.9 & 8.0 & 3.2 & \\
\hline & Female & OG & 328 & 9.3 & 8.0 & 3.2 & $p>0.05$ \\
\hline & & $\mathrm{CR}$ & 158 & 9.3 & 8.0 & 3.6 & \\
\hline \multirow[t]{4}{*}{ Reduced activity } & Male & OG & 106 & 9.6 & 9.0 & 2.9 & $p>0.05$ \\
\hline & & $\mathrm{CR}$ & 90 & 8.9 & 8.0 & 3.3 & \\
\hline & Female & OG & 328 & 9.3 & 8.0 & 3.3 & $p>0.05$ \\
\hline & & $\mathrm{CR}$ & 158 & 9.3 & 8.0 & 3.7 & \\
\hline \multirow[t]{4}{*}{ Mental fatigue } & Male & OG & 106 & 9.8 & 9.0 & 2.7 & $p>0.05$ \\
\hline & & CR & 90 & 8.5 & 8.0 & 3.0 & \\
\hline & Female & OG & 328 & 9.5 & 8.0 & 2.9 & $p>0.05$ \\
\hline & & $\mathrm{CR}$ & 158 & 9.5 & 8.0 & 3.3 & \\
\hline \multirow[t]{4}{*}{ Reduced motivation } & Male & OG & 106 & 9.4 & 8.0 & 2.9 & $p>0.05$ \\
\hline & & $C R$ & 90 & 8.3 & 8.0 & 3.3 & \\
\hline & Female & OG & 328 & 8.9 & 8.0 & 2.9 & $p>0.05$ \\
\hline & & $\mathrm{CR}$ & 158 & 8.5 & 8.0 & 3.5 & \\
\hline
\end{tabular}

OG: Oil and gas, CR: Control region.

Table 4: Fatigue dimension values of the subjective rating scale in the study regions

\begin{tabular}{|c|c|c|c|c|c|c|}
\hline \multirow[t]{3}{*}{ No } & \multirow[t]{3}{*}{ Dimension } & \multirow[t]{3}{*}{ Scale answer numbers } & \multicolumn{4}{|c|}{ n scores } \\
\hline & & & OG & CR & OG & CR \\
\hline & & & Male & Male & Female & Female \\
\hline 1 & General fatigue & $1,5,12,16$ & 9.7 & 9.3 & 8.4 & 8.9 \\
\hline 2 & Physical fatigue & $2,8,14,20$ & 9.8 & 9.5 & 8.5 & 9.5 \\
\hline 3 & Reduced activity & $3,6,10,17$ & 9.7 & 9.3 & 8.9 & 9.3 \\
\hline 4 & Mental fatigue & $7,11,13,19$ & 9.4 & 8.9 & 8.3 & 8.5 \\
\hline 5 & Reduced motivation & $4,9,15,18$ & 9.0 & 9.3 & 8.9 & 9.3 \\
\hline
\end{tabular}

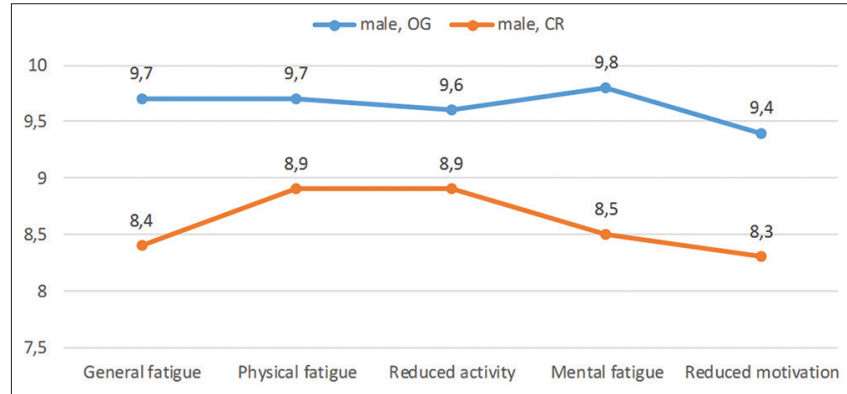

Figure 1: Quantitative male self-report values in oil and gas and control regions

For illustrative purposes, the data on fatigue dimension values by gender given in Table 4 are presented in the form of a diagram in Figures 1 and 2.

A comparison of the data (by the MannWhitney $U$ test) revealed that there were statistically significant differences $(p>0.05)$ in terms of "general fatigue," "reduced motivation," and "mental fatigue" among men and in terms of "general fatigue" and "reduced motivation" among women in the study regions [20], [21]. According to descriptive statistics, the average score in the OG region was lower than in the $C R$.

\section{Discussion}

Based on data analysis, the psychological profiles of the population of the OG region were identified and described. Each profile has its own features that

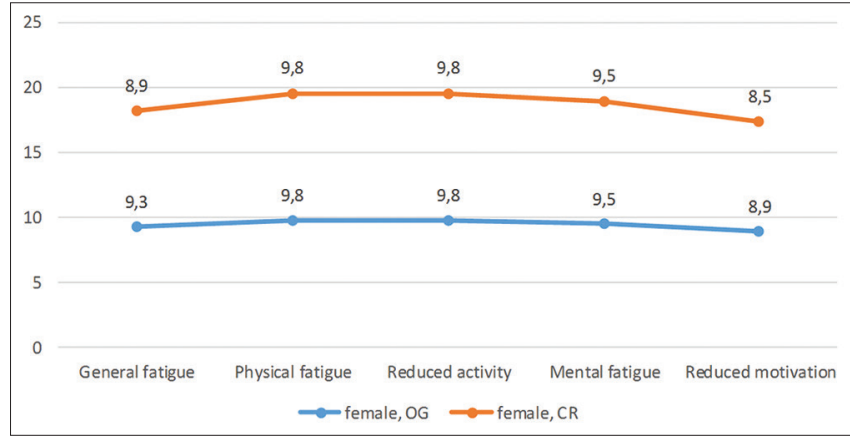

Figure 2. Quantitative female self-report values in oil and gas and control regions

characterize the psychophysical state of an individual. One should note the importance of understanding fatigue, given its adverse effects. Fatigue should not be confused with tiredness. Tiredness is a physiological phenomenon that occurs as a result of the depletion of energy reserves, a transient process, disappearing after rest, and not requiring medical assistance. Fatigue is a feeling of weakness and extreme tiredness, which is not associated with any load; it may arise in the state of rest and does not disappear after sleep. This feeling is most often psychogenic in nature, and in this case, a person might need medical assistance.

In the process of data analysis, there were difficulties in interpreting some items of the MFI-20. For example, such items as "I feel fit" (item 1), "I think I do very little in a day" (item 10), and "I am rested" (item 12) sound somewhat problematic. Difficulties arose when it was necessary to identify the cause of the psychophysical state of an individual: Whether it was associated with environmental influences or it was fatigue as such. In addition, item 20 "Physically, 
I feel I am in an excellent condition" is probably more connected with general thoughts about one's condition. Despite the difficulties noted, the values of the scale indicators were combined into two groups (profiles): Anxious and passive-aggressive.

"Anxious" is an emotional state characteristic of an individual prone to experiencing anxiety. Described by Freud, the term "anxiety" literally means "readiness for anxiety." The state of anxiety arises in a situation when a certain irritant is perceived by an individual as a threat, danger, or harm, and can intensify in the case when a person does not understand the reasons for his or her poor health. Situations of uncertainty as well as adverse living and working conditions increase feelings of anxiety and fear, which can cause side effects. The steady state of anxiety leads to the constant production of stress hormones. A person starts to have frequent headaches, insomnia, and reduced physical activity. This is noticeable among women, especially of middle age, which can be associated not only with their attitude to changes in the environment but also with a sense of powerlessness, which creates potential health problems at the psychophysical level. The body weakens with age, which leads to the occurrence of endocrine diseases (diabetes, hypertrichosis, and bronchial asthma). In addition, there is a decrease in an individual's adaptive mechanisms, i.e., in the level of psychophysical adaptation, which negatively affects his or her relationships in the external environment and leads to social diseases, such as the inability to create strong family ties, communicative behavior disorders, and emotional disturbances. According to neuroimaging data, the long duration of such a condition leads to organic changes in the brain, which may result in more serious consequences for an individual's health [22], [23], [24], [25], [26].

Passive-aggressive behavior is characterized by indirect resistance to the demands of other people and the prevention of direct confrontation. The passiveaggressive behavior pattern was first described by Colonel William Menninger in relation to soldiers, whose behavior at first glance was not openly defiant, yet expressed aggression with passive measures stubbornness, pouting, procrastination, and inefficiency. Menninger defined such behavior as "immaturity" as a reaction to "routine military stress." According to Menninger, there are two groups of stress: Internal and external. Each of them carries either a challenge or a threat to the life of an individual, limiting his or her activity. In the case of soldiers, "immaturity" is an internal factor and "routine military stress" is an external factor. In our case, external factors include an unconscious impulse to action, which is manifested in actions in the emotional and communicative spheres. In our opinion, this is a result of the long-term environmental and, consequently, social disadvantage of the population living in the $O G$ region. Internal factors include unconscious emotional experiences, accompanied by prolonged stress, which carries the risk of harming one's own health. In addition, people of this profile are characterized by an inadequate reaction to stress, such as distraction and irritable weakness. According to I.P. Pavlov, they involve pathological lability or explosiveness, increased anxiety, fear, which may not seem to be manifested in any way - these are signs of irrational behavior leading to social maladaptation, as well as a tendency to depression and fatigue. Such a condition is dangerous because under the influence of both external and internal factors and with an insufficient volume of compensatory reactions, it can transform into more complex clinical manifestations in the form of depressive symptoms, which contributes to the appearance of a premorbid state. In this situation, an individual is not always able to independently resist this [27], [28], [29].

Thus, the state of the environment in the OG region negatively affects the psychophysical health of the local population. This condition is aggravated by unfavorable living conditions, the feeling of helplessness, and the inability to influence the course of events. The discussion shows that the results of this study are supported by the existing literature on the influence of external factors on the psychophysical health of the population, which suggests that it depends on the state of the environment.

\section{Conclusions}

The research results made it possible to conclude that external factors (OG development), due to the region's environmental destabilization, negatively affect the psychophysical state of health of the local population. This showed a comparison of two independent groups in the OG region and in the $\mathrm{CR}$, which have significantly different values of fatigue $(p<0.05)$. It also became clear that the deterioration of the psychophysical state of the population of the OG region is associated with a feeling of inability to control the situation. Psychological profiles identified in practice have a direct correlation with the indicators of the MFI20 scale $(p<0.0)$. An anxious profile was associated with mental fatigue and reduced motivation, while passive-depressive - with physical and general fatigue. The research data indicate that the study region poses a significant risk to public health.

\section{References}

1. Moore CW, Zielinska B, Pétron G, Jackson RB. Air impacts of increased natural gas acquisition, processing, and use: A critical review. Environ Sci Technol. 2014;48(15):8349-59. https://doi. org/10.1021/es4053472

PMid:24588259 
2. Field RA, Soltis J, Murphy S. Air quality concerns of unconventional oil and natural gas production. Environ Sci Process Impacts. 2014;16(5):954-69. https://doi.org/10.1039/ c4em00081a

PMid:24699994

3. Czolowski ED, Santoro RL, Srebotnjak T, Shonkoff SB. Toward consistent methodology to quantify populations in proximity to oil and gas development: A national spatial analysis and review. Environ Health Perspect. 2017;125(8):086004. https://doi. org/10.1289/ehp1535

PMid:28858829

4. Finkel ML, Hays J. The implications of unconventional drilling for natural gas: A global public health concern. Public Health. 2013;127(10):889-93. https://doi.org/10.1016/j.puhe.2013.07.005 PMid:24119661

5. Alekseenko VD, Simonova NN, Zueva TN. Influence of industrial factors on health status of oil production workers during rotations in the Polar region. Hum Ecol. 2009;6:47-50.

6. Tsalik S, Schiffrin A. Covering oil: A Reporter's Guide to Energy and Development. Revenue Watch, Open Society Institute, Initiative for Policy Dialogue. New York: Open Society Institute; 2005. Available from: https://www.spectrumsdkn.org/ en/library/natural-resource-management-library/32-coveringoil-a-reporters-guide-to-energy-and-development/file. [Last accessed 2020 Feb 02]

7. Tustin AW, Hirsch AG, Rasmussen SG, Casey JA, BandeenRoche K, Schwartz BS. Associations between unconventional natural gas development and nasal and sinus, migraine headache, and fatigue symptoms in Pennsylvania. Environ Health Perspect. 2017;125(2):189-97. https://doi.org/10.1289/ ehp281

PMid:27561132

8. Simonova NN. Psychological Aspects of Rotations of Oil Workers in the Far North. Moscow: Paleotip; 2008.

9. Webinar: Community and Psychosocial Effects of Oil and Gas Development. http://www.ceh.org/webinar-psychosocialcommunity-effects-of-unconventional-energy-extractiondevelopment. [Last accessed 2020 Feb 02].

10. Verkuil B, Brosschot JF, Meerman EE, Thayer JF. Effects of momentary assessed stressful events and worry episodes on somatic health complaints. Psychol Health. 2012;27(2):141-58. https://doi.org/10.1080/08870441003653470

PMid:21038174

11. Bunch AG, Perry CS, Abraham L, Wikoff DS, Tachovsky JA, Hixon JG. Evaluation of impact of shale gas operations in the Barnett Shale region on volatile organic compounds in air and potential human health risks. Sci Total Environ. 2014;468469:832-42. https://doi.org/10.1016/j.scitotenv.2013.08.080 PMid:24076504

12. Lazarus RS. Theory-based stress measurement. Psychol Inq 1990;1(1):3-13.

13. da Silva JA, Siegmund G, Bredemeier J. Crisis interventions in online psychological counseling. Trends Psychiatry Psychother. 2015;37(4):171-82. https://doi. org/10.1590/2237-6089-2014-0026

\section{PMid:26689385}

14. Kershbaum H, Chugunova El. The teachings of I.P. Pavlov on higher nervous activity. Academician I.P. Pavlov Russian Medical and Biological Bulletin. 2014;3:103-5.

15. Aleksandrovsky YA. Frontier Psychiatry. Moscow: RLS; 2006.

16. The Health Impact Assessment of New Energy Sources: Shale Gas Extraction. Institute of Medicine Website; 2013. Available from: http://www.iom.edu/activities/environment/ environmentalhealthRT/2012-APR-30.aspx. [Last accessed 2020 Feb 24].

17. Snezhnevsky AV. General Psychopathology: A Lecture Course. $9^{\text {th }}$ ed. Moscow: MED Pressinform; 2017.

18. Zinovyev PM. On Asthenic Syndromes. A Collection Dedicated to the $50^{\text {th }}$ Anniversary of S.S. Korsakov Psychiatric Clinic, Moscow; 1940.

19. Shulgina GI. Behavioral Inhibition. Moscow: Intell; 2016.

20. Asselmann E, Venz J, Pieper L, Wittchen HU, Pittrow D, Beesdo-Baum K. The role of gender and anxiety in the association between somatic diseasesand depression: Findings from three combined epidemiological studies in primary care. Epidemiol Psychiatr Sci. 2017;9:1-12. https://doi.org/10.1017/ s2045796017000567

21. Vander Ham L, Wright $P$, Van TV, Doan VD, Broerse JE. Perceptions of mental health and help-seeking behavior in an urban community in Vietnam: An explorative study. Community Ment Health J. 2011;47(5):574-82. https://doi.org/10.1007/ s10597-011-9393-x

PMid:21409418

22. Freud S. Inhibitions, Symptoms and Anxiety (1926 [1925]); Attractions and Neuroses. Moscow: Akademicheskiy Proyekt; 2007.

23. Smulevich AB. Psychosomatic Disorders in Clinical Practice. Moscow: MED Press-Inform; 2016.

24. Passive-aggressive. Definition of Passive-aggressive in English by Oxford Dictionaries. Oxford Dictionaries. Available from: https://www.oxfordlearnersdictionaries.com/definition/english/ passive-aggressive. [Last accessed $2020 \mathrm{Feb} 21$ ].

25. Smulevich AB, Dubnitskaia EB. Actual problems of systematics of depression. S.S. Korsakov J Neurol Psychiatry. 2012;11(2):11-20.

26. Resick L, Knestrick J, Counts M, Pizzuto L. The meaning of health among mid-Appalachian women within the context of the environment. J Environ Stud Sci. 2013;3(3):32-45. https://doi. org/10.1007/s13412-013-0119-y

27. Menninger WC. In: Hall BH, Rhodes R, editors. Living in a Troubled World Selections from the Writings of William C. Menninger. Vol. 12. Hallmark Editions; 1967. p. 59.

28. Long JE, Long NJ, Signe W. The Psychology of PassiveAggressive Behavior in Families, Schools, and Workplaces. Austin, Texas: PRO-ED Inc.; 2008.

29. Hopwood CJ, Morey LC, Markowitz JC, Pinto A, Skodol AE, Gunderson JG, et al. The construct validity of passiveaggressive personality disorder. Psychiatry. 2009;72(3):256-68. https://doi.org/10.1521/psyc.2009.72.3.256 PMid:19821648 